\title{
Validation studies on gender determination from fingerprints with special emphasis on ridge characteristics
}

\author{
Mukesh Kumar Thakar, , Parveen Kaur and Tina Sharma
}

\begin{abstract}
Background: The present work investigates the ridge characteristics and ridge density of fingerprints to determine gender differences among population of Punjab. The main characteristics studied were general pattern type, ridge density and minutiae or ridge characteristics with respect to general pattern type. Further, instead of using conventional method of ridge counting, Adobe Photoshop cs5 is used to conclude ridge density and minutiae characteristics. Experimental results shows, along with ridge density, minutiae characteristics procure special importance in determining the gender from fingerprints.

Results: The results suggest that mean ridge density in males is 12.32 ridges $/ 25 \mathrm{~mm}^{2}$. where as it was 13.94 ridges/ $25 \mathrm{~mm}^{2}$ in females. The study has supported the hypothesis that women tend to have thin ridges i.e. more ridge density as compared to men. The study of minutiae or ridge characteristics revealed that frequency of ridge ending (50.24 index fingers, 50.62 middle fingers) and enclosures (2.87\% in index and 3.08\% in middle finger) is higher in females as compared to males. Further significant gender difference has been observed in minutiae characteristics with respect to general pattern type. Among both genders; males tend to have more number of minutiae as compared to females in case of loop and whorl as general pattern type. In case of Arch pattern females tends to have more number of minutiae as compared to males.

Conclusions: The research carried by the authors of this paper synchronizes with the findings of other researchers despite differences in populations selected. More number of minutiae and ridges were found in case of females as compared to male fingerprints. In the present study an attempt has been made to validate the method by analyzing the blind samples which likewise showed more number of minutiae in case of females as compared to males. Although the study agrees with common theory of more ridge details in females as compared to males, yet low success rate in case of blind trial has unveiled further scope of research required to determine gender from fingerprints found at scene of crime or disputed documents.
\end{abstract}

Keywords: Forensic science, Ridge density, Minutiae characteristics, Gender differences in fingerprints, Gender determination

\section{Background}

Gender determination is one of the significant aspects of fingerprint identification science having extensive applications in diverse scientific fields. Apart from forensic science it has applications in human biology and anthropological sciences to study various traits among different populations and cultures (Lee and Gaensslen 2014). Apart from all these, fingerprints are valued forensically because of their

\footnotetext{
* Correspondence: mukeshk38@gmail.com

Department of Forensic Science, Punjabi University, Patiala, India
}

frequent presence at scene of crime and help in the identification of the suspect (Champod et al. 2004). The features like pattern type, pattern intensity index and ridge counts, which acquire comparatively more importance and are widely used features (Galera et al. 2008). However, other features such as minutiae and epidermal ridge width (ridge density) have not been generally studied more in comparison to the feature mentioned above, despite being features of considerable significance due to their direct relevance in personal identification. Okajima (1970) studied the basic minutiae present in the prints taken from twins belonging 
to various populations and noted higher correlations between the numbers of minutiae present in the prints of monozygotic and dizygotic twins. More minutiae were observed in prints from males as compared to females, but no bilateral differences (right vs. left) have been observed (Okajima 1970). Correlations between the presence or absence of pattern area and number of minutiae have also been investigated (Kralik and Novotny 2003). Hypothetically the females have comparatively finer body parts than males, in terms of body weight and body parts etc. Similarly in case of fingerprint in females constitute $2.7 \pm .09$ more ridges than in the males (Cummins and Midlo 1943). It can be correlated to the smaller hand size in female, but still, it is also partly independent of hand size, since ridges tend to be narrower in females when compared with males having the same hand size (Nayak and Rastogi 2010; Galton 1892; Nayak et al. 2010; Kaur and Garg 2011; Sangam et al. 2011; Daluz 2014). Study carried out by Acree et al. on caucasian individuals and african american individuals suggests that a given fingerprint possessing a ridge density of 11 ridges $/ 25 \mathrm{~mm}^{2}$ or less is most likely to be of male origin. Likewise a fingerprint having a ridge density of 12 ridges $/ 25 \mathrm{~mm}^{2}$ or greater is most likely to be of female origin, regardless of race, and hand dimensions (Acree 1999).

To test the hypothesis in the people of Northern India, the present study has been carried out on fingerprints samples of index and middle fingers of randomly selected males and females. The main objective of the study was to examine the variations present in minutiae and ridge density among the both sexes and correlates it with different pattern types with the help of Adobe Photoshop cs5 software. After testing the hypothesis, blind trial was done to further validate its applicability at scene of crime and disputed documents containing thumb impressions (in case of illiterate individuals) as signatures.

\section{Material and methods Collection of samples}

In the present Study, Fingerprints samples from only healthy individuals were collected from northern population of India (Punjab) to study the gender differences based on ridge density and minutiae or ridge characteristics. Persons having skin diseases, burnt and amputated fingers were excluded from the study. The plain as well as rolled fingerprint samples of index and middle finger of both the hands were taken out of which 200 fingerprints belonged to males and remaining 200 were of females. Fingerprints were collected with the help of plain glass plate of $15 \mathrm{~cm} * 15 \mathrm{~cm}$. Block printer ink (Daler Rowney manufactured) ink was smeared on glass plate with the help of a roller. The subjects were asked to roll their finger from the radial side (thumb) to the ulnar side (little finger) on the smeared plate and then transferred their finger prints in the same manner onto the specified space on the bond paper (85gsm). The age of the subject varied from 16 to 18 years. The criteria to choose only index and middle finger for the purpose of gender determination were based on the probability of their occurrence at the scene of crime (Reddy 1975). In most of the cases the index and middle fingerprints are mostly encountered on number of substrates like pen, mobile, screen/covers, doors and window/ window panes etc. and probability of index and middle fingerprints get transferred is much higher than rest of the fingers.

The samples were obtained randomly from different schools, colleges of Patiala, Gurdaspur, Mohali and Jalandhar cities of Punjab, India. Further, collected fingerprints were scanned with 300dpi resolution in jpeg format. The scanned fingerprint images were converted to grey scale with Adobe Photoshop cs5. The size of images was standardized with the help of ruler tool from analysis and image size was standardized to make life size image of fingerprint by setting pixels between 4000 by 3000 . The core of fingerprint was kept at 90 degree with the help of arbitrary image rotation tool.

\section{Analysis of fingerprint samples}

The serially marked fingerprint samples were analysed according to the methodology given by Acree. Two straight lines were drawn which bisect each other, this bisecting point was set at core or approximate centre of the fingerprint (Fig. 1). Adobe Photoshop cs5 was used to superimpose the scale on fingerprint to analyse ridge details according to Thakar and Sharma methodology (Thakar and Sharma 2016) as shown in Fig. 2. The soft copy of grid was opened in the new window and selected with magic wand tool. The selection was thus pasted on the fingerprint to be examined. Further, Bifurcations and lakes were counted as two ridges and dot as one ridge. The ridge density and minutiae or ridge characteristics present in the selected area was counted in each fingerprint (Table 2). Mean value for ridge density and Standard deviation value have been calculated for each pattern and tabulated in Tables 1, 2, 3 and 4. These values have been used for inter-se comparison of fingerprints.

Further, minutiae characteristics have also been studied to determine a correlation between the gender and fingerprints.

\section{Statistical analysis}

In this paper, an attempt has been made to study the general patterns and their frequency along with ridge density and minutiae or ridge characteristics to differentiate gender from finger prints. This has been statistical achieved by calculating minimum, maximum, mean and standard deviation from finger prints of index and middle finger 


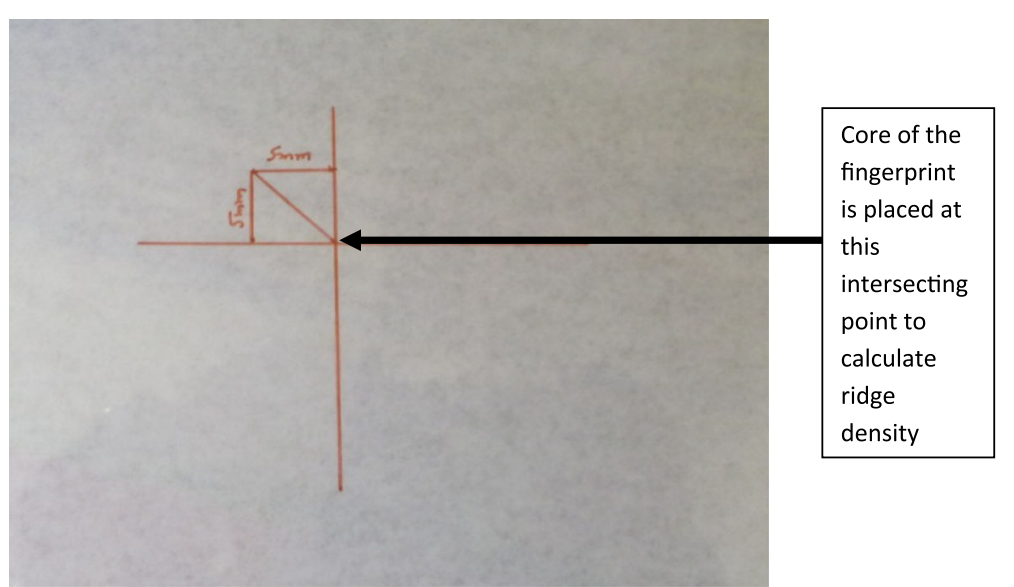

Fig. 1 The sample scanned image of scale used to conclude ridge densities as per Acree's method (1999). A square was drawn (5mmX5mm) with total Square area constituting $25 \mathrm{~mm}^{2}$

belonging to males and females. The Microsoft Office Excel 2007 has been used in estimating statistically the average total number and frequencies of the each minutia types present in the whole sample and for each gender, along with their frequencies in different pattern types (arches, loops, and whorls).

\section{Blind trials to validate gender determination with respect to ridge density and minutiae characteristics}

Finger print samples were collected from random individuals of Punjabi University, Patiala. 5 Fingerprint Samples both from male and females were collected and packed in envelops individually without disclosing gender of fingerprint donor. Q1 to Q5 codes were assigned to packed envelops enclosing fingerprints and a file mentioning donor data was maintained separately. The analysis was performed as per the above mentioned methodology.

\section{Results}

The results obtained from the analysis of fingerprints for gender determination have been given in Tables 1, 2, 3 and 4 and indicate the followings.

The Gender differences in general pattern types among 400 individuals have been shown in Table 1. Ulnar loop was found to be the most frequently encountered pattern and found to be more frequent in females as compared to males. Arch pattern was observed among $8.4 \%$ of the total population studied and found to be more frequent in males as compared to females, whereas Radial loop was observed to be the least frequent pattern (4\%) of the total population studied and was found to be less frequent in male than in females.

The data Ridge Density in index and middle finger of both 400 males and females have been given in Table 2 . The data suggest that ridge density of females is higher

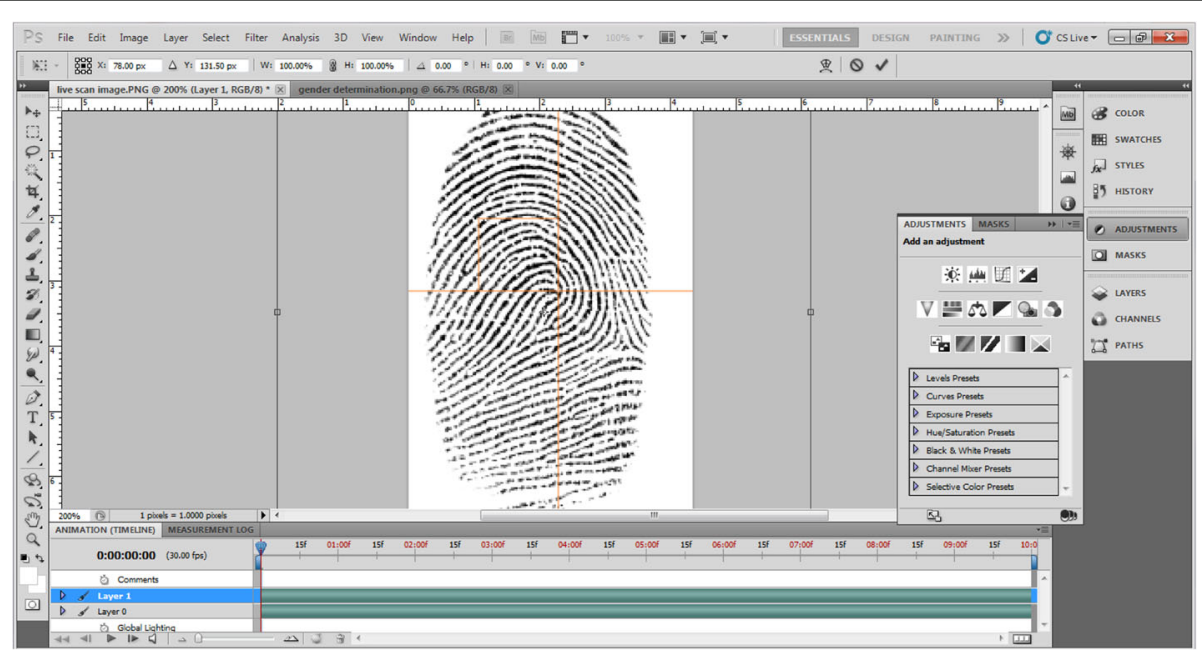

Fig. 2 Showing superimposition of scale according to method suggested by Thakar and Sharma (2016) with the help of Adobe Photoshop cs5 software. Magic wand tool was used to select the scale so that it can be superimposed on the scanned image of selected fingerprint 
Table 1 Show the Gender differences in general pattern types among 400 individuals

\begin{tabular}{llll}
\hline \multirow{2}{*}{ Patterns } & \multicolumn{2}{l}{ Gender Differences } & \\
\cline { 2 - 4 } & Total No. & Males & Female \\
& Of Samples & Samples & Samples \\
\hline Arch & 34 & 20 & 14 \\
Radial Loop & 16 & 6 & 10 \\
Ulnar loop & 226 & 110 & 116 \\
Whorls & 124 & 64 & 60 \\
\hline
\end{tabular}

as compared to males with respect to both index and middle finger studies.

\section{Calculation of minutiae or ridge characteristics}

The minutiae or ridge characteristics present in fingerprints of index and middle finger was identified and has been given in Table 3 .

The frequencies of minutiae characteristics present in Index and Middle finger of both genders have also been given in Table 3. It is evident from the data that females tend to have more percentage of ridge endings, bridge, and enclosures as compared to males in both the fingers. Whereas other minutiae Bifurcation, Short ridge, Point /Dot, Break, Overlap and Crossbar tend to have more number in males as compared to females in both the fingers. But in case of opposite bifurcation both the fingers have different percentage in males and females.

The descriptive data related to statistical analysis of minutiae present in the fingerprints with respect to general pattern type of Index and Middle fingers of both the sexes have been given in Table 4. The data indicates that particularly, in case of loop and whorl pattern types exhibit significant gender differences.

\section{Discussions}

\section{Calculations of ridge density}

In the past too many studies have been conducted on ridge count by various scientists like Cummins and Midlo to establish that females do have higher mean ridge count. The results synchronize with the present study as higher ridge count was found in females (23.4) than males (20.7). But according to Acree et al., the mean ridge count for male is 11.14 and that of female is 13.32 in Caucasian population. Acc to the present study, the results as shown in Table 2, suggest that mean ridge density of male index finger is 12.32 ridges $/ 25 \mathrm{~mm}^{2}$, whereas in female it was 13.94 ridges $/ 25 \mathrm{~mm}^{2}$ in Punjabi population. The mean ridge density of male in case of middle finger is 12.7 ridges $/ 25 \mathrm{~mm}^{2}$ and in females 13.22 ridges $/ 25 \mathrm{~mm}^{2}$. The study supported the observations made by the earlier workers that women tend to have more ridge density as compared to men validating the fact in Punjabi population as well.

\section{Calculation of pattern types}

The pattern types of fingerprints and their frequencies have been calculated and tabulated in Table 1. The most frequent pattern types was found to be the ulnar loop (56.5\%) which is followed by the whorl(31\%). Radial loops were among the rare (4\%) pattern and have least frequency among the samples collected.

\section{Calculation of minutiae characteristics types}

The frequency of ridge ending (50.24 index fingers, 50.62 middle fingers) and enclosures $(2.87 \%$ in index and $3.08 \%$ in middle finger) is higher in females as compared to males. Although he minutiae types of crossbar and bridge are also higher in females than in males but the frequency of its occurrence is much lower to be significantly included in discretion process yet more sampling in near future may clear the clouds of their role in gender differentiation (Figs. 3 and 4).

\section{Calculation of minutiae characteristics with respect to general pattern type}

Three patterns were studied to reach out gender differences with respect to number of minutiae and type of minutiae present in Punjabi population as shown in Table 4.

In case of Arches, more number of minutiae was found in females as compared to males. Among all the three minutiae characteristics' ridge endings were observed to be more in females (17.55) than in males (16.4). In loops and whorl pattern types, more number of minutiae was observed in males than in females. In loop pattern type, ridge endings were observed to be more in males (20.42) than in females (19.75). Similarly in case of whorls, with 18.46 mean values of ridge endings of males, females tend to had lesser ridge endings.

Table 2 Shows description of Ridge Density in index and middle finger of 400 individual's both males and females

\begin{tabular}{|c|c|c|c|c|c|c|c|c|c|}
\hline & \multirow[b]{2}{*}{$\begin{array}{l}\text { Total } \\
\mathrm{N}\end{array}$} & \multicolumn{8}{|c|}{ Ridge density } \\
\hline & & $\begin{array}{l}\text { Min. } \\
\text { (I) }\end{array}$ & $\begin{array}{l}\text { Min. } \\
\text { (M) }\end{array}$ & $\begin{array}{l}\text { Max } \\
\text { (I) }\end{array}$ & $\begin{array}{l}\text { Max } \\
\text { (M) }\end{array}$ & $\begin{array}{l}\text { Mean } \\
\text { (I) }\end{array}$ & $\begin{array}{l}\text { Mean } \\
\text { (M) }\end{array}$ & $\begin{array}{l}\text { S.D } \\
(I)\end{array}$ & $\begin{array}{l}\text { S.D } \\
(M)\end{array}$ \\
\hline Males & 400 & 11.06 & 11.15 & 14.04 & 14.37 & 12.32 & 12.7 & 1.72 & 1.26 \\
\hline Females & 400 & 11.25 & 11.6 & 14.45 & 13.91 & 13.94 & 13.22 & 1.55 & 1.05 \\
\hline
\end{tabular}

*I Index finger, ${ }^{* *} M$ Middle finger 
Table 3 Showing Frequencies of minutiae or Ridge Characteristics present in the Fingerprints of Index and Middle finger of both Males and Females

\begin{tabular}{llllll}
\hline Minutiae & \multicolumn{2}{l}{ Index Finger } & & \multicolumn{2}{l}{ Middle finger } \\
\cline { 2 - 3 } \cline { 6 - 7 } & $\begin{array}{llllll}\text { Males } \\
(\%)\end{array}$ & $\begin{array}{l}\text { Females } \\
(\%)\end{array}$ & & $\begin{array}{l}\text { Males } \\
(\%)\end{array}$ & $\begin{array}{l}\text { Females } \\
(\%)\end{array}$ \\
\hline Ridge ending & 48.75 & 50.24 & & 49.67 & 50.62 \\
Bifurcation & 41.67 & 41.56 & & 41.54 & 40.54 \\
Short ridge & 4.63 & 3.74 & & 3.76 & 3.52 \\
Point /Dot & 1.73 & 0.65 & & 1.18 & 1.13 \\
Break & 0.35 & 0.1 & & 0.19 & 0.16 \\
Enclosure & 2.34 & 2.87 & & 2.62 & 3.08 \\
Overlap & 0.05 & 0.1 & & 0.09 & 0.1 \\
Crossbar & 0.1 & 0.05 & & 0.14 & 0.16 \\
Bridge (Two bifurcations & 0.25 & 0.48 & 0.49 & 0.54 \\
together joined with one ridge) & & & & \\
Opposite bifurcation & 0.1 & 0.16 & 0.24 & 0.1 \\
\hline
\end{tabular}

Blind trials to validate gender determination with respect to ridge density and minutiae characteristics

It was observed that only in $60 \%$ of samples, gender determination was correctly opined. All the females included in the study were correctly identified nut in two cases males were not accurately identified as shown in Table 5. As the previous studies suggest that the ridge density and ridge characteristics are found more in females than in males, extreme high ridge density can be opined as female gender but lower score fingerprints with respect to minutiae and ridge density do not ensure male characteristics. Similar blind trial studies with respect to all ethnic races should be conducted to reach out at definite opinion.

Gender determination with Adobe Photoshop CS5 provides enormous possibilities of better working environment as compared to the conventional method (Plato et al. 1975). Besides this, present study supported the hypothesis

Table 4 Describe the Statistical Results of minutiae with respect to general pattern type

\begin{tabular}{|c|c|c|c|c|c|c|}
\hline \multirow{2}{*}{$\begin{array}{l}\text { Minutiae } \\
\text { characteristics }\end{array}$} & \multicolumn{2}{|c|}{ Arches } & \multicolumn{2}{|l|}{ Loop } & \multicolumn{2}{|l|}{ Whorl } \\
\hline & Mean & S.D. & Mean & S.D. & Mean & S.D. \\
\hline \multicolumn{7}{|l|}{ Males } \\
\hline Ridge ending & 16.4 & 5.59 & 20.42 & 3.55 & 18.46 & 3.68 \\
\hline Bifurcation & 14.2 & 2.16 & 17.01 & 4.47 & 16.06 & 3.96 \\
\hline Short ridge & 4.5 & 3.04 & 2.43 & 1.88 & 2.57 & 1.62 \\
\hline \multicolumn{7}{|l|}{ Females } \\
\hline Ridge ending & 17.55 & 3.5 & 19.75 & 6.13 & 16.44 & 5.51 \\
\hline Bifurcation & 15.66 & 5.04 & 15.17 & 4.58 & 14.89 & 4.42 \\
\hline Short ridge & 1.71 & 1.11 & 1.97 & 1.46 & 1.93 & 1.19 \\
\hline
\end{tabular}

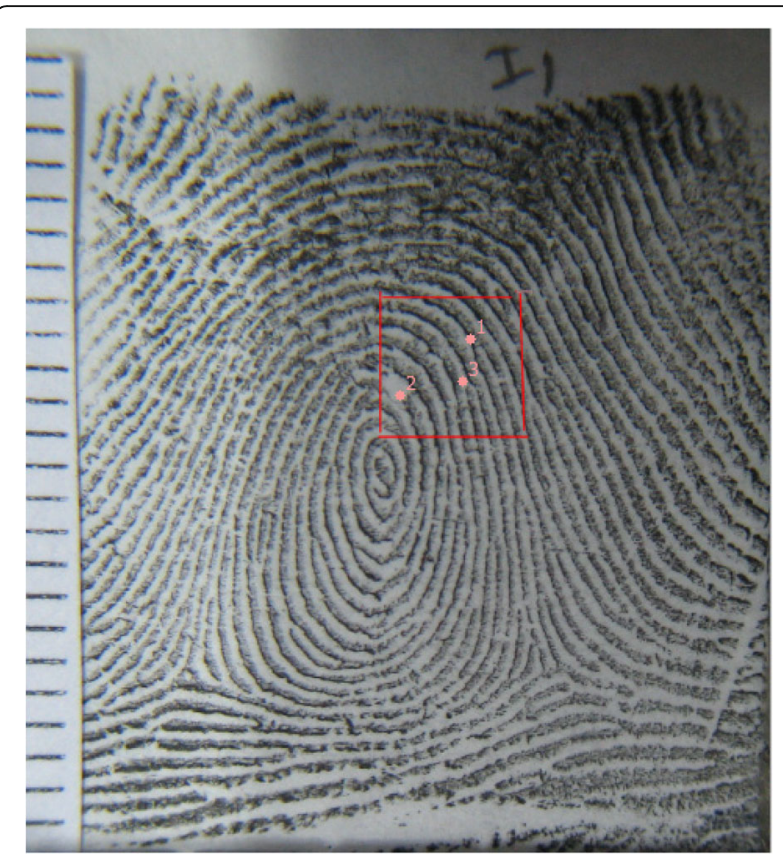

Fig. 3 Showing print of Index finger of female Subject and 3 bifurcation marked red colour with the help of count tool in Adobe Photoshop cs5

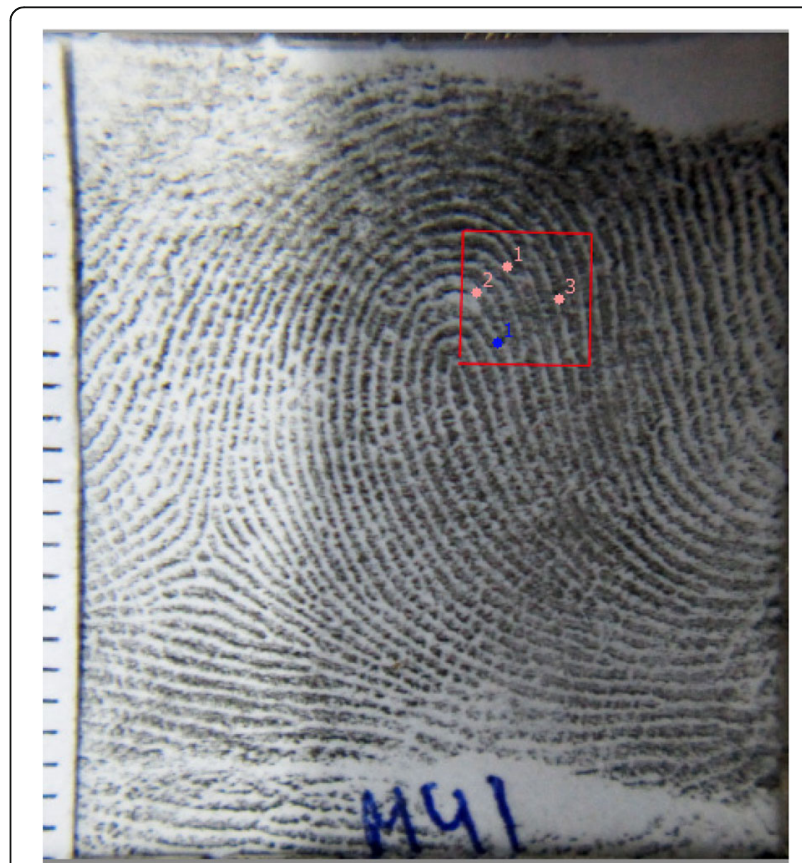

Fig. 4 Showing print of Middle finger of male Subject and 3 bifurcation marked pink colour with one ridge ending in blue colour with the help of count tool in Adobe Photoshop cs5 
Table 5 Shows the blind trials conducted on 5 fingerprint samples

\begin{tabular}{llllll}
\hline & $\begin{array}{l}\text { Ridge } \\
\text { density }\end{array}$ & Bifurcations & $\begin{array}{l}\text { Ridge } \\
\text { endings }\end{array}$ & $\begin{array}{l}\text { Opinion with } \\
\text { blind trial }\end{array}$ & Identity \\
\hline Q1 & 11 & 3 & 1 & No opinion & Male \\
Q2 & 11 & 3 & 3 & Female & Male \\
Q3 & 13 & 2 & 3 & Female & Female \\
Q4 & 7 & 2 & 0 & Male & Male \\
Q5 & 8 & 2 & 1 & Male & Male \\
\hline
\end{tabular}

of lesser ridge density in males as well as highlights the importance of ridge characteristics to conclude gender differences. Cummins and Midlo (1943) have established that females do have higher mean ridge count (23.4) than males (20.7). Okajima (1970) also found that fork index is higher in females than in male in fingerprints. This again upholds the trend as in this present study. But certain authors also reported negative results regarding this hypothesis, According to Reddy (1975), the mean ridge count for males is 13.41 and that of female are 12.04. These figures were exactly the opposite of Acree (1999). A similar study has been undertaken on males and females belonging to American Negroes and Caucasian American by Plato et al. (1975). Here again they found that the mean ridge density in male is more than female. But in the present study, results synchronized with researchers who concluded lesser ridge density of males as compared to females. Further, pattern and ridge characteristics has also correlation with gender differences were also studied, which suggested that irrespective of finger, the frequency of ulnar loop was found to be perceptibly higher in males than in females. Similarly, frequency of radial loop was more in females than in males. The irrespective of fingers and gender, ridge endings and enclosures were found to be the most common minutiae characteristics present in the fingerprints and found more frequently in males as compared to females.

\section{Conclusions}

The results obtained from present analysis by taking in to account the various parameters associated with this research and comparison made with early findings leads to the conclusions that ridge endings, bifurcations have shown considerably higher frequencies in both the genders while other minutiae were present in much lesser frequencies. The use of computer software Adobe Photoshop cs5 helped in studying fingerprints in lesser time and more effectively as compared to manual method of analysis. The average number of minutiae was found to be more in females as compared to males but conclusive inferences can be reached by further increasing the sample size. For being accepted as procedural tool there has to be universal element in an established principle. Although the study agrees with common theory of more ridge details in females as compared to males, yet low success rate in case of blind trial has unveiled further scope of research required to determine gender from fingerprints found at scene of crime or disputed documents.

The noteworthy differences have been observed in ridge densities as well as combination minutiae characteristics with respect to general pattern type. Therefore it is suggested that the scope of the research can be expanded by increasing fingerprint sample size, hand dimensions(width/length) etc. to arrive at a certain conclusions regarding its use as forensic tool for gender determination.

\section{Acknowledgements \\ Not applicable.}

Funding

Not applicable.

Availability of data and materials

The datasets generated during and/or analyzed during the current study are available from the corresponding author on reasonable request.

\section{Authors' contributions}

Study conception and design: MKT, TS. Acquisition of data: PK. Analysis and interpretation of data: PK, TS, MKT. Drafting of manuscript: PK, TS. Critical revision: MKT, TS. All authors read and approved the final manuscript.

\section{Ethics approval and consent to participate}

Ethical approval was not required and consents from all the participants were obtained as per ethical guidelines.

\section{Consent for publication}

Written informed consent was obtained from the participants for the publication of this report and any accompanying images.

\section{Competing interests}

The authors declare that they have no competing interests.

\section{Publisher's Note}

Springer Nature remains neutral with regard to jurisdictional claims in published maps and institutional affiliations.

Received: 8 June 2017 Accepted: 1 February 2018

Published online: 19 February 2018

\section{References}

Acree MA (1999) Is there a gender difference in finger print ridge density? Forensic Sci Int 102:35-44

Champod C, Lennard PA, Stoilovic MM (2004) Fingerprints and other ridge skin impressions, 2nd ed. CRC Press, Washington

Cummins H, Midlo C (1943) Finger Prints. Palms and Soles. Dover Publications 2nd ed. p 309

Daluz HM (2014) Fundamentals of fingerprint analysis, $1^{\text {st }}$ ed. CRC Press, London, pp 256-257

Galera V, Romero E, Alonso C (2008) Variability of fingerprint ridge density in a sample of Spanish Caucasians and its application to sex determination. Forensic Sci Int 180:17-22

Galton F (1892) Finger Prints. MacMillan, London, p 1892

Kaur R, Garg RK (2011) Determination of gender differences from fingerprint ridge density in two northern Indian populations. Problems of Forensic Sciences LXXXV, pp 5-10 
Kralik M, Novotny V (2003) Epidermal ridge breadth: an indicator of age and sex in paleodermatoglyphics. Var Evol 11:5-30

Lee HC, Gaensslen RE (2014) Advances in fingerprint technology, $2^{\text {nd }}$ ed. London, CRC Press 45-49

Nayak VC, Rastogi P (2010) Sex differences from fingerprint ridge density in the Indian population. J Forensic Leg Med 17:84-86

Nayak VC, Rastogi P, Kanchan T (2010) Sex differences from fingerprint ridge density in Chinese and Malaysian population. Forensic Sci Int 197:67-69

Okajima M (1970) Frequency of forks in epidermal-ridge minutiae in the finger print. Am J Phys Anthropol 32:41-48

Plato CC, Cereglino JJ, Steinberg FS (1975) The Dermatoglyphics of American Caucasian. Am J Phy Antrhop 42:192-210

Reddy CC (1975) Finger Dermatoglyphics of the Bagathas of Araku Valley. India. Am J Phys Anthropol 42:225-228

Sangam MR, Krupadanam K, Anasuya K (2011) A study of finger prints: bilateral asymmetry and sex difference in the region of andhra pradesh. J Clin Diagn Res 5:597-600

Thakar MK, Sharma T (2016) Digital grid method for fingerprint identification and objective report writing. Egypt J Forensic Sci 6(2):194-201

\section{Submit your manuscript to a SpringerOpen ${ }^{\circ}$ journal and benefit from:}

- Convenient online submission

- Rigorous peer review

- Open access: articles freely available online

- High visibility within the field

- Retaining the copyright to your article

Submit your next manuscript at $\gg$ springeropen.com 